\title{
Comparison of in vivo hindfoot joint motion changes during stance phase between normal foot and stage II adult acquired flatfoot
}

\section{Zhenhan Deng ( $\boldsymbol{\nabla}$ dengzhenhan@email.szu.edu.cn )}

Shenzhen Second People's Hospital https://orcid.org/0000-0003-0522-8269

\section{Zijun Cai}

Xiangya Hospital Central South University

\section{Siyu Chen}

Shenzhen Second People's Hospital

\section{Yan Liu}

Shenzhen Second People's Hospital

\section{Fanglin Chen}

The Fourth Affiliated Hospital of Guangxi Medical University, Liuzhou Workers' Hospital

\section{Zhiqin Deng}

Shenzhen Second People's Hospital

\section{Yusheng Li}

Xiangya Hospital Central South University

\section{Jian Xu}

Guangxi Medical University

\section{Research}

Keywords: adult acquired flatfoot deformity, movement, in vivo, hindfoot joint

Posted Date: March 7th, 2022

DOI: https://doi.org/10.21203/rs.3.rs-1398759/v1

License: (c) (i) This work is licensed under a Creative Commons Attribution 4.0 International License. Read Full License 


\section{Abstract}

Background: To compare the kinematic characteristics of hindfoot joints in stage $\nabla$ adult acquired flatfoot deformity (AAFD) with those of normal foot through the 3D-to-2D registration technology and single fluoroscopic imaging system.

Methods: CT scans were performed on the bilateral feet of 7 normal volunteers and 8 volunteers with stage $\nabla$ AAFD in neutral positions. Their lateral dynamic X-ray data during the stance phase, including 14 normal feet and 10 flatfeet, was collected. A computer-aided simulated light source for 3D CT model was applied to obtain the virtual images, which were matched with the dynamic X-ray images to register in the "Fluo" software, so that the spatial changes during the stance phase could be calculated.

Results: During the early-stance phase, the calcaneous was more dorsiflexed, everted, and externally-rotated relative to the talus in flatfoot compared with that in normal foot, and the difference is statistically significant $(p<0.05)$. During the mid-stance phase, the calcaneous was more dorsiflexed and everted relative to the talus in flatfoot compared with that in normal foot, and the difference is statistically significant $(p<0.05)$; however, the rotation did not differ significantly between the two groups ( $p>0.05)$. During the late-stance phase, the calcaneous was more plantarflexed, but less inverted and internally-rotated, relative to the talus in flatfoot compared with that in normal foot, and the difference is statistically significant $(p<0.05)$. During the early- and mid-stance phase, the navicular was more dorsiflexed, everted, and externally-rotated relative to the talus in flatfoot compared with that in normal foot, and the difference is statistically significant $(\mathrm{p}<0.05)$. During the late-stance phase, the navicular was more plantarflexed, but less inverted and internally-rotated, relative to the talus in flatfoot compared with that in normal foot, and the difference is statistically significant $(\mathrm{p}<0.05)$. There was no difference in the motion of cuboid between the two groups during the whole stance phase $(p>0.05)$.

Conclusions: During the early- and mid-stance phase, excessive motion was observed in the subtalar and talonavicular joints in stage $\triangle A A F D$. During the late-stance phase, the motion of subtalar and talonavicular joints appeared to be in the decompensated state. During the whole stance phase, the motion of calcaneocuboid joint showed no significant difference between normal foot and stage $\triangle$ AAFD.

\section{Background}

Adult acquired flatfoot deformity (AAFD) is a common degenerative disease with multiple stages that causes poor alignment of joints, which will lead to the generation of pain and ultimately affect the normal function and activity of the foot and ankle [1]. AAFD is a common progressive pathology that mainly affects patients after their 50s, and was estimated to affect up to 5 million people in the US [2,3]. AAFD has long been recognized as a key causative factor even though its etiology has not been fully elucidated to date, while the great majority of patients have their talonavicular joint (TNJ) sub dislocated in one or more planes. $[2,4,5]$.

In 1989, based on the study of tibialis posterior tendon dysfunction, Johnson and Strom set a three-stage classifification for AAFD [6]. Among them, Stage $₫$ AAFD refers to the transitional period from a flexible deformity to a stiff deformity, which is most widely studied in clinical practice but is also the most controversial one for its treatment [7-9]. During this period, the chief clinical manifestations are early forefoot abduction deformity, midfoot collapse, and hindfoot valgus deformity. In the early stages of AAFD (Stages I, Ila and IIb), many treatment options focus on rebalancing the foot structure. However, when the deformity is rigid (stage III or IV), surgeons have to use more restrictive treatments such as arthrodesis of the hindfoot joints [10-12]. The anatomic abnormalities of hindfoot joints are closely related to the AAFD onset, while the disruption of the linkage mechanism is a major factor in its progression. Thus, the research of the characteristics of the motion of hindfoot joints can be of great importance. The hindfoot joints 
are mainly comprised of three joints, namely the subtalar joint (STJ), the TNJ and the calcaneo-cuboid joint (CCJ). Wang et al. detected Synchronous and homodromous rotational motions of the TNJ, STJ, and CCJ during the stance phase [13].

By comparing the hindfoot joints motion between normal volunteers and AAFD patients under a simulated full-body weight-bearing static condition, Zhang et al. [14] reported excessive motion in the TNJ and STJ among AAFD patients, but the dynamic condition in the gait stance phase remained unclear. Wang et al. [13] found that TNJ had a greater mobility in the sagittal plane while STJ had a greater mobility in the coronal plane in stage II AAFD patients by applying the 3D-to-2D registration technique based on dynamic x-rays. Although this study analyzed the motion difference in the tarsal complex between normal feet and flatfeet in the stance phase, it failed to reflect the detailed motion change and trend during the whole stance phase, which can be divided into heel-strike (HS), foot-flat (FF), midstance (MS), heel-off (HO), and toe-off (TO).

Our study, by utilizing the advanced 3D-to-2D registration technique as well [13, 15-18], aimed to investigate the motion characteristics of hindfoot joints in the stance phase more comprehensively based on the above mentioned 5 events in stage $\triangle A A F D$. Understanding the biomechanics of the hindfoot is critical to the proper care of patients with a variety of orthopedic impairments and foot deformities resulting from conditions such as cerebral palsy, spina bififida, club foot, traumatic brain injury and spinal cord injury $[19,20]$.

\section{Methods}

Seven normal adult volunteers (4males and 3 females; mean age: $44.3 \pm 7.3$ (range, 26 to 52) years) who were free of foot and ankle deformities, tumors, acute and chronic injuries, and gait abnormalities were enrolled in the present study. There were also 8 volunteers with stage II AAFD who were free of foot and ankle tumors and acute and chronic injuries ( 4 males and 4 females; mean age: $41.2 \pm 8.5$ (range, 21 to 56) years). A total of 10 flatfeet were obtained, including 4 left and 6 right feet. All the recruited subjects had signed the informed consent form approved by the Institutional Review Board (IRB) of Liuzhou Worker's Hospital prior to the formal research. Table 1 shows the subjects' characteristics in each group. The FluoMotion software (Innomotion Inc., Shanghai) was used to perform the 3D-to-2D registration. 
Table 1

Differences in hindfoot bone motion data measured by RSA technique and Fluo software single-plane registration technique

\begin{tabular}{|c|c|c|c|c|c|c|c|c|c|c|c|c|}
\hline \multirow[t]{2}{*}{ Bone } & \multicolumn{6}{|c|}{ Translation(mm) } & \multicolumn{6}{|c|}{ Rotation $\left(^{\circ}\right)$} \\
\hline & $\Delta \mathbf{x}$ & $\mathbf{P}$ & $\Delta y$ & $\mathbf{P}$ & $\Delta \mathbf{z}$ & $\mathbf{P}$ & $\Delta \mathbf{a}$ & $\mathbf{P}$ & $\Delta \beta$ & $\mathbf{P}$ & $\Delta \mathbf{Y}$ & $\mathbf{P}$ \\
\hline Talus & $\begin{array}{l}3.00 \pm \\
2.21\end{array}$ & 0.23 & $\begin{array}{l}0.57 \pm \\
1.73\end{array}$ & 0.29 & $\begin{array}{l}-0.21 \\
\pm 0.38\end{array}$ & 0.47 & $\begin{array}{l}-0.45 \\
\pm 0.7\end{array}$ & 0.65 & $\begin{array}{l}0.48 \\
\pm \\
2.92\end{array}$ & 0.27 & $\begin{array}{l}-0.87 \\
\underline{ \pm} \\
2.32\end{array}$ & 0.44 \\
\hline Calcaneus & $\begin{array}{l}1.5 \pm \\
0.51\end{array}$ & 0.55 & $\begin{array}{l}0.22 \pm \\
0.4\end{array}$ & 0.67 & $\begin{array}{l}-0.16 \\
\pm 0.41\end{array}$ & 0.91 & $\begin{array}{l}-0.20 \\
\pm 0.23\end{array}$ & 0.34 & $\begin{array}{l}0.86 \\
\pm \\
1.82\end{array}$ & 0.75 & $\begin{array}{l}-0.27 \\
\pm \\
1.12\end{array}$ & 0.57 \\
\hline Navicular & $\begin{array}{l}3.07 \pm \\
2.52\end{array}$ & 0.79 & $\begin{array}{l}0.38 \pm \\
1.12\end{array}$ & 0.46 & $\begin{array}{l}-0.87 \\
\pm 0.90\end{array}$ & 0.48 & $\begin{array}{l}-0.25 \\
\pm 1.25\end{array}$ & 0.37 & $\begin{array}{l}0.90 \\
\pm \\
2.30\end{array}$ & 0.72 & $\begin{array}{l}-0.70 \\
\pm \\
1.94\end{array}$ & 0.95 \\
\hline Cuboid & $\begin{array}{l}2.19 \pm \\
2.4\end{array}$ & 0.77 & $\begin{array}{l}0.63 \pm \\
1.47\end{array}$ & 0.35 & $\begin{array}{l}-1.57 \\
\pm 3.07\end{array}$ & 0.37 & $\begin{array}{l}0.02 \pm \\
0.9\end{array}$ & 0.48 & $\begin{array}{l}0.16 \\
\pm 3.4\end{array}$ & 0.53 & $\begin{array}{l}-0.70 \\
\pm \\
1.94\end{array}$ & 0.48 \\
\hline
\end{tabular}

The accuracy of the kinematic data measured by 3D model registration was validated on a cadaveric specimen obtained from a selected lower leg (male, 68 years old) by adopting the radiographic stereophotogrammetry analysis (RSA) technique.

Accuracy and repeatability assessment of the 3D model and 2D image registration technique applied to the hindfoot by RSA

The RSA technique, with an accuracy ranging from 0.05 to $0.5 \mathrm{~mm}$ and a $0.15^{\circ}$ turning range [17], was utilized to verify the accuracy as well as the reproducibility of the 3D-to-2D registration technique. This technique requires the implantation of a certain amount of tantalum beads at a fixed position inside the bone tissue or around an artificial joint prosthesis as a marker.

Fresh intact calf specimens were obtained from a 68-year-old man and 4 tantalum beads with the size of $1 \mathrm{~mm}$ were implanted into the talus, calcaneus, navicular bone, and cuboid bone respectively for $\mathrm{CT}$ imaging. The scanning range was from the sole of the foot to $10 \mathrm{~cm}$ above the ankle, and the layer thickness was set as $0.67 \mathrm{~mm}$. The images were imported into Mimics 17.0 software with coronal, sagittal and cross-sectional planes (Fig. 1A-C). Then, the three dimensional models were reconstructed. The virtual coordinates were constructed in the neutral position as a reference by regarding the center of mass of each bone as the origin of the coordinate system (Fig. 1D). The rotation in the coordinate system was considered as the dorsiflexion and plantarflexion around the $\mathrm{X}$-axis, the inversion and eversion around the $\mathrm{Y}$-axis, and the internal rotation and external rotation around the Z-axis respectively. The dorsiflexion, inversion, and internal rotation were defined as positive, whereas the plantarflexion, eversion, and external rotation were defined as negative.

The single plane X-ray imaging system consists of an X-ray emission device as well as an adjustable gait platform that can adjust the height to accommodate the height of the fluoroscopic C-arm machine. After fixing a calibration device in the receiver section of the $\mathrm{C}$-arm machine, the foot of the specimen was placed onto a gait platform to artificially simulate its dynamic processes and to perform the lateral imaging of X-ray in real-time (Fig. 2A). The dynamic images were taken at a frequency of $10 \mathrm{~Hz}$ with $1000 \times 1000$ pixels for each image. 
Five images were randomly selected for registration to verify the accuracy in the dynamic simulation process. The corresponding 3D model was matched to the respective bone block images on the radiographs for contouring (Fig. 2B). This software is able to automatically calculate the relative $3 \mathrm{D}$ translation and rotation of the bone blocks in the six degrees of freedom. $\Delta \mathrm{X}, \Delta \mathrm{Y}, \Delta \mathrm{Z}$ represent the difference of translation on $\mathrm{X}, \mathrm{Y}$ and $\mathrm{Z}$ axes respectively, and $\Delta \mathrm{a}, \Delta \beta, \Delta \mathrm{Y}$ represent the difference of rotation angle on $\mathrm{X}, \mathrm{Y}$ and $\mathrm{Z}$ axes respectively.

\section{Dynamic measurements of hindfoot joints during the stance phase in normal and stage II AAFD volunteers}

CT images were collected from 7 normal adults and 8 stage II AAFD volunteers with forefoot abduction deformity, medial arch collapse and hindfoot valgus (Fig. 3). All the volunteers were trained to walk for three consecutive steps in order to match the X-ray dynamic imaging capture system. The X-ray dynamic fluoroscopy was performed during the second step of walking. Before that, the gait speed should maintain at $0.5 \mathrm{~m} / \mathrm{s}$. Then, 7 key gait postures in all fluoroscopic images were picked up for registration analysis to compare between the flatfoot and normal foot (Fig. 4). The motion (Fig. 5) in the hindfoot joints was calculated automatically by the software.

\section{Statistical analysis}

All statistical data was analyzed by SPSS 20.0. The results were expressed by mean \pm standard deviation. The range of motion (ROM) of normal foot and flatfoot was determined by two independent sample t-test methods. The multivariate analysis of variance was used to perform pairwise comparison of the hindfoot joints in the stance phase between the normal foot and flatfoot. When $p<0.05$, a statistically significant difference was indicated.

\section{Results}

\section{Verification of accuracy and repeatability of the registration of 3D model with 2D image in the single plane perspective system}

The difference in the motion data of the bone block and hindfoot joints was calculated using the RSA technique and the 3D-to-2D image single plane registration technology (Table 1, 2). Among the 4 tarsal bones of talus, navicular, cuboid, and calcaneus, the cuboid had the largest translation deviation in the same plane of X-ray imaging, which can be up to $-1.57 \pm 3.07 \mathrm{~mm}$; the talus had the largest rotation deviation, which can be up to $-0.45 \pm 0.7^{\circ}$. In any other planes perpendicular to this plane, the navicular had the largest translation deviation, which can be up to $3.07 \pm 2.52 \mathrm{~mm}$; the talus had the largest rotation deviation, which can be up to $-0.87 \pm 0.32^{\circ}$. In the hindfoot, the maximum translation deviation of the talonavicular joint in the same plane of X-ray imaging can be up to $-0.13 \pm 0.4 \mathrm{~mm}$, while the talus had the largest rotation deviation, which can be up to $-1.87 \pm 1.05^{\circ}$. In any other planes perpendicular to this plane, the subtalar joint had the largest translation and rotation deviation, which can be up to $2.05 \pm 0.95 \mathrm{~mm}$ and $-1.8 \pm 2.33^{\circ}$, respectively. 
Table 2

Differences of hindfoot motion data measured by RSA technique and Fluo software single plane registration technique

\begin{tabular}{|c|c|c|c|c|c|c|c|c|c|c|c|c|}
\hline \multirow[t]{2}{*}{ Joint } & \multicolumn{6}{|c|}{ Translation(mm) } & \multicolumn{6}{|c|}{ Rotation $\left(^{\circ}\right)$} \\
\hline & $\Delta \mathbf{x}$ & $P$ & $\Delta y$ & $\mathbf{P}$ & $\Delta \mathbf{z}$ & $\mathbf{P}$ & $\Delta \mathbf{a}$ & $\mathbf{P}$ & $\Delta \beta$ & $\mathbf{P}$ & $\Delta Y$ & $\mathbf{P}$ \\
\hline Subtalar joint & $\begin{array}{l}2.05 \\
\pm \\
0.95\end{array}$ & 0.51 & $\begin{array}{l}-0.28 \\
\pm \\
0.19\end{array}$ & 0.42 & $\begin{array}{l}0.19 \\
\pm \\
0.51\end{array}$ & 0.23 & $\begin{array}{l}-1.87 \\
\pm \\
1.05\end{array}$ & 0.63 & $\begin{array}{l}0.76 \\
\pm \\
2.24\end{array}$ & 0.19 & $\begin{array}{l}-1.8 \\
\pm \\
2.33\end{array}$ & 0.61 \\
\hline $\begin{array}{l}\text { Talonavicular } \\
\text { joint }\end{array}$ & $\begin{array}{l}-1.01 \\
\pm 0.2\end{array}$ & 0.59 & $\begin{array}{l}0.33 \\
\pm 0.4\end{array}$ & 0.67 & $\begin{array}{l}0.27 \\
\pm \\
0.78\end{array}$ & 0.48 & $\begin{array}{l}-0.24 \\
\pm \\
2.03\end{array}$ & 0.46 & $\begin{array}{l}-1.0 \\
\pm \\
3.26\end{array}$ & 043 & $\begin{array}{l}-0.17 \\
\pm \\
2.17\end{array}$ & 0.75 \\
\hline $\begin{array}{l}\text { Calcaneocuboid } \\
\text { joint }\end{array}$ & $\begin{array}{l}1.00 \\
\pm \\
0.72\end{array}$ & 0.37 & $\begin{array}{l}-0.29 \\
\pm \\
0.38\end{array}$ & 0.56 & $\begin{array}{l}-0.29 \\
\pm \\
0.86\end{array}$ & 0.60 & $\begin{array}{l}0.56 \\
\pm \\
2.89\end{array}$ & 0.52 & $\begin{array}{l}-0.12 \\
\pm \\
2.91\end{array}$ & 0.57 & $\begin{array}{l}0.61 \\
\pm \\
2.69\end{array}$ & 0.83 \\
\hline
\end{tabular}

Average Trend Of The Hindfoot Joints Motion

Figure 6 shows the trend of 7 key gait postures of each joint in the stance phase on the $X, Y$, and $Z$ axes. Table 3 presents the comparison of the ROM of hindfoot between the normal foot and stage II flatfoot. It can be seen that the flatfoot had a larger ROM in the subtalar joint on X-axis $\left(8.11 \pm 1.39^{\circ}\right.$ vs $\left.6.93 \pm 2.47^{\circ}, p<0.05\right)$ and Y-axis $\left(19.77 \pm 5.08^{\circ}\right.$ vs $\left.13.65 \pm 3.64^{\circ}, p<0.05\right)$ as well as a larger ROM in the talonavicular joint on $X$-axis $\left(13.56 \pm 4.14^{\circ}\right.$ vs $9.19 \pm 2.86^{\circ}, p<$ $0.05)$ and $Y$-axis $\left(31.91 \pm 8.45^{\circ}\right.$ vs $\left.18.41 \pm 3.80^{\circ}, p<0.05\right)$ than the normal foot.

Table 3

Comparison of range of motion of hindfoot between the normal foot and stage II flatfoot.

\begin{tabular}{|c|c|c|c|c|c|c|c|c|c|}
\hline & \multicolumn{3}{|c|}{ ROM of subtalar joint $\left({ }^{\circ}\right)$} & \multicolumn{3}{|c|}{ ROM of talonavicular joint $\left({ }^{\circ}\right)$} & \multicolumn{3}{|c|}{$\begin{array}{l}\text { ROM of calcaneocuboid joint } \\
\left({ }^{\circ}\right)\end{array}$} \\
\hline & $\mathrm{X}$-axis & Y-axis & Z-axis & $\mathrm{X}$-axis & Y-axis & Z-axis & $\mathrm{X}$-axis & Y-axis & Z-axis \\
\hline Normal & $\begin{array}{l}6.93 \pm \\
2.47\end{array}$ & $\begin{array}{l}13.65 \pm \\
3.64\end{array}$ & $\begin{array}{l}10.74 \pm \\
2.52\end{array}$ & $\begin{array}{l}9.19 \pm \\
2.86\end{array}$ & $\begin{array}{l}18.41 \pm \\
3.80\end{array}$ & $\begin{array}{l}16.11 \pm \\
4.44\end{array}$ & $\begin{array}{l}4.89 \pm \\
1.44\end{array}$ & $\begin{array}{l}8.22 \pm \\
2.3\end{array}$ & $\begin{array}{l}9.11 \pm \\
3.30\end{array}$ \\
\hline Flatfoot & $\begin{array}{l}8.11 \pm \\
1.39\end{array}$ & $\begin{array}{l}19.77 \pm \\
5.08\end{array}$ & $\begin{array}{l}10.12 \pm \\
2.99\end{array}$ & $\begin{array}{l}13.56 \pm \\
4.14\end{array}$ & $\begin{array}{l}31.91 \pm \\
8.45\end{array}$ & $\begin{array}{l}17.13 \pm \\
5.38\end{array}$ & $\begin{array}{l}5.29 \pm \\
1.82\end{array}$ & $\begin{array}{l}8.49 \pm \\
2.68\end{array}$ & $\begin{array}{l}9.45 \pm \\
3.44\end{array}$ \\
\hline $\mathbf{P}$ & 0.023 & 0.001 & 0.21 & 0.001 & 0.001 & 0.16 & 0.45 & 0.33 & 0.76 \\
\hline
\end{tabular}

Rom Of Hindfoot From The First To The Third Posture (Hs To Ff)

Table 4 details the ROM of hindfoot from the first to the third posture (HS to FF). In the subtalar joint, the flatfoot had a higher ROM on all the X-axis $\left(3.33 \pm 2.78^{\circ}\right.$ vs $\left.3.09 \pm 1.72^{\circ}, p<0.05\right)$, Y-axis $\left(11.40 \pm 5.11^{\circ}\right.$ vs $\left.4.80 \pm 2.28^{\circ}, p<0.05\right)$ and Zaxis $\left(6.76 \pm 2.82^{\circ}\right.$ vs $\left.5.45 \pm 2.13^{\circ}, \mathrm{p}<0.05\right)$ than the normal foot (Fig. 8A). Similarly, in the talonavicular joint, the flatfoot also had a higher ROM on all the X-axis $\left(7.27 \pm 3.78^{\circ}\right.$ vs $\left.3.45 \pm 1.93^{\circ}, p<0.05\right)$, $Y$-axis $\left(14.15 \pm 8.20^{\circ}\right.$ vs $8.32 \pm 3.30^{\circ}, p<$ $0.05)$ and Z-axis $\left(7.40 \pm 4.36^{\circ}\right.$ vs $\left.5.12 \pm 2.86^{\circ}, p<0.05\right)$ than the normal foot (Fig. 8B). However, in the calcaneocuboid joint, there was no difference between the normal foot and flatfoot on $X$-axis $\left(1.93 \pm 1.49^{\circ}\right.$ vs $\left.1.98 \pm 1.77^{\circ}, p>0.05\right), Y$ axis $\left(3.22 \pm 2.18^{\circ}\right.$ vs $\left.3.20 \pm 2.17^{\circ}, p>0.05\right)$ and Z-axis $\left(3.24 \pm 1.95^{\circ}\right.$ vs3.10 $\left.\pm 2.21^{\circ}, p>0.05\right)$ (Fig. $\left.8 \mathrm{C}\right)$. 
Table 4

ROM of the hindfoot from the first to the third step, from the third to the fifth step, and from the fifth to the seventh step.

\begin{tabular}{|c|c|c|c|c|c|c|c|c|c|}
\hline & \multicolumn{3}{|c|}{ ROM of subtalar joint $\left(^{\circ}\right)$} & \multicolumn{3}{|c|}{ ROM of talonavicular joint $\left(^{\circ}\right)$} & \multicolumn{3}{|c|}{$\begin{array}{l}\text { ROM of calcaneocuboid } \\
\text { joint ( }\left(^{\circ}\right)\end{array}$} \\
\hline & Normal & Flatfoot & $P$ & Normal & Flatfoot & $\mathbf{P}$ & Normal & Flatfoot & $\mathbf{P}$ \\
\hline Motion31(X) & $\begin{array}{l}3.09 \pm \\
1.72\end{array}$ & $\begin{array}{l}3.33 \pm \\
2.78\end{array}$ & 0.031 & $\begin{array}{l}3.45 \pm \\
1.93\end{array}$ & $\begin{array}{l}7.27 \pm \\
3.78\end{array}$ & 0.001 & $\begin{array}{l}1.93 \pm \\
1.49\end{array}$ & $\begin{array}{l}1.98 \pm \\
1.77\end{array}$ & 0.57 \\
\hline Motion31(Y) & $\begin{array}{l}-4.80 \pm \\
2.28\end{array}$ & $\begin{array}{l}-11.4 \pm \\
5.11\end{array}$ & 0.001 & $\begin{array}{l}-8.32 \pm \\
3.30\end{array}$ & $\begin{array}{l}-14.15 \pm \\
8.20\end{array}$ & 0.001 & $\begin{array}{l}-3.22 \pm \\
2.18\end{array}$ & $\begin{array}{l}-3.20 \pm \\
2.17\end{array}$ & 0.65 \\
\hline Motion31(Z) & $\begin{array}{l}-5.45 \pm \\
2.13\end{array}$ & $\begin{array}{l}-6.76 \pm \\
2.82\end{array}$ & 0.021 & $\begin{array}{l}-5.12 \pm \\
2.86\end{array}$ & $\begin{array}{l}-7.40 \pm \\
4.36\end{array}$ & 0.002 & $\begin{array}{l}-3.24 \pm \\
1.95\end{array}$ & $\begin{array}{l}-3.10 \pm \\
2.21\end{array}$ & 0.24 \\
\hline Motion53(X) & $\begin{array}{l}1.51 \pm \\
1.91\end{array}$ & $\begin{array}{l}2.69 \pm \\
1.49\end{array}$ & 0.013 & $\begin{array}{l}3.06 \pm \\
1.52\end{array}$ & $\begin{array}{l}3.84 \pm \\
5.34\end{array}$ & 0.034 & $\begin{array}{l}2.00 \pm \\
1.75\end{array}$ & $\begin{array}{l}2.15 \pm \\
1.44\end{array}$ & 0.32 \\
\hline Motion53(Y) & $\begin{array}{l}-3.90 \pm \\
3.04\end{array}$ & $\begin{array}{l}-6.42 \pm \\
2.95\end{array}$ & 0.020 & $\begin{array}{l}-5.55 \pm \\
5.90\end{array}$ & $\begin{array}{l}-15.56 \pm \\
15.48\end{array}$ & 0.0001 & $\begin{array}{l}-3.25 \pm \\
3.31\end{array}$ & $\begin{array}{l}-3.29 \pm \\
3.70\end{array}$ & 0.34 \\
\hline Motion53(Z) & $\begin{array}{l}-1.45 \pm \\
2.52\end{array}$ & $\begin{array}{l}-1.49 \pm \\
0.80\end{array}$ & 0.45 & $\begin{array}{l}-4.15 \pm \\
5.56\end{array}$ & $\begin{array}{l}-5.31 \pm \\
5.54\end{array}$ & 0.01 & $\begin{array}{l}-1.91 \pm \\
3.54\end{array}$ & $\begin{array}{l}-2.00 \pm \\
3.90\end{array}$ & 0.57 \\
\hline Motion75(X) & $\begin{array}{l}-5.75 \pm \\
2.99\end{array}$ & $\begin{array}{l}-6.83 \pm \\
1.50\end{array}$ & 0.03 & $\begin{array}{l}-8.79 \pm \\
2.95\end{array}$ & $\begin{array}{l}-11.60 \pm \\
5.18\end{array}$ & 0.001 & $\begin{array}{l}-4.47 \pm \\
1.58\end{array}$ & $\begin{array}{l}-3.87 \pm \\
1.59\end{array}$ & 0.11 \\
\hline Motion75(Y) & $\begin{array}{l}12.36 \pm \\
3.19\end{array}$ & $\begin{array}{l}8.09 \pm \\
7.67\end{array}$ & 0.001 & $\begin{array}{l}11.55 \pm \\
5.33\end{array}$ & $\begin{array}{l}7.34 \pm \\
8.31\end{array}$ & 0.002 & $\begin{array}{l}6.95 \pm \\
2.79\end{array}$ & $\begin{array}{l}7.10 \pm \\
3.10\end{array}$ & 0.33 \\
\hline Motion75(Z) & $\begin{array}{l}8.96 \pm \\
3.08\end{array}$ & $\begin{array}{l}6.45 \pm \\
1.94\end{array}$ & 0.01 & $\begin{array}{l}13.48 \pm \\
5.49\end{array}$ & $\begin{array}{l}10.47 \pm \\
5.50\end{array}$ & 0.008 & $\begin{array}{l}7.75 \pm \\
2.85\end{array}$ & $\begin{array}{l}8.12 \pm \\
2.87\end{array}$ & 0.56 \\
\hline \multicolumn{10}{|c|}{$\begin{array}{l}\text { Motion } 31(X) \text {, motion } 31(Y) \text { and motion } 31(Z) \text { respectively represent the motion changes of each joint on the } X, Y \\
\text { and } Z \text { axes from the first step to the third step; Motion } 53(X) \text {, motion } 53(Y) \text { and motion } 53(Z) \text { respectively represent } \\
\text { the motion changes of each joint on the } X, Y \text { and } Z \text { axes from the third step to the fifth step; Motion } 75(X) \text {, motion } 75 \\
(Y) \text { and motion } 75(X) \text { represent the motion changes of each joint on the } X, Y \text { and } Z \text { axes from the fifth step to the } \\
\text { seventh step. } P<0.05 \text { showed statistical difference. }\end{array}$} \\
\hline
\end{tabular}

Rom Of Hindfoot From The Third To The Fifth Posture (Mid-stance Phase)

Table 4 details the ROM of hindfoot from the third to the fifth posture. In the subtalar joint, the flatfoot had a higher ROM on X-axis $\left(2.69 \pm 1.49^{\circ}\right.$ vs $\left.1.51 \pm 1.91^{\circ}, p<0.05\right)$ and $Y$-axis $\left(6.42 \pm 2.95^{\circ}\right.$ vs $\left.3.90 \pm 3.04^{\circ}, p<0.05\right)$ than the normal foot, but no difference was observed on Z-axis $\left(1.49 \pm 0.80^{\circ}\right.$ vs $1.45 \pm 2.52^{\circ}, p>0.05$, Fig. $\left.8 \mathrm{~A}\right)$. In the talonavicular joint, the flatfoot had a higher ROM on all the X-axis $\left(3.84 \pm 5.34^{\circ}\right.$ vs $\left.3.06 \pm 1.52^{\circ}, p<0.05\right)$, Y-axis $\left(15.56 \pm 15.48^{\circ}\right.$ vs $5.55 \pm$ $\left.5.90^{\circ}, p<0.05\right)$ and Z-axis $\left(5.31 \pm 5.54^{\circ}\right.$ vs $\left.4.15 \pm 5.56^{\circ}, p<0.05\right)$ than the normal foot (Fig. 8B). However, in the calcaneocuboid joint, there was no difference between the normal foot and flatfoot on $X$-axis $\left(2.00 \pm 1.75^{\circ} \mathrm{vs} 2.15 \pm\right.$ $\left.1.44^{\circ}, p>0.05\right)$, Y-axis $\left(3.25 \pm 3.31^{\circ}\right.$ vs $\left.3.29 \pm 3.70^{\circ}, p>0.05\right)$ and Z-axis $\left(1.91 \pm 3.54^{\circ}\right.$ vs $\left.2.00 \pm 3.90^{\circ}, p>0.05\right)($ Fig. $8 \mathrm{C})$.

Rom Of Hindfoot From The Fifth To The Seventh Posture (Ms To To)

Table 4 also details the ROM of hindfoot from the fifth to the seventh posture. In the subtalar joint, the flatfoot had a higher ROM on all the X-axis $\left(6.83 \pm 1.50^{\circ}\right.$ vs $\left.5.75 \pm 2.99^{\circ}, p<0.05\right)$, Y-axis $\left(8.09 \pm 7.67^{\circ}\right.$ vs $\left.12.36 \pm 3.19^{\circ}, p<0.05\right)$ and Zaxis $\left(6.45 \pm 1.94^{\circ}\right.$ vs $\left.8.96 \pm 3.08^{\circ}, p<0.05\right)$ than the normal foot (Fig. $\left.8 \mathrm{~A}\right)$. In the talonavicular joint, the flatfoot had a higher ROM on X-axis $\left(11.60 \pm 5.18^{\circ}\right.$ vs $\left.8.79 \pm 2.95^{\circ}, p<0.05\right)$, but a lower ROM on $Y$-axis $\left(7.34 \pm 8.31^{\circ}\right.$ vs $11.55 \pm 5.33^{\circ}$ $p<0.05)$ and Z-axis $\left(10.47 \pm 5.50^{\circ}\right.$ vs $\left.13.48 \pm 5.49^{\circ}, p<0.05\right)$, than the normal foot (Fig. $\left.8 B\right)$. However, in the calcaneocuboid joint, there was no difference between the normal foot and flatfoot on X-axis $\left(4.47 \pm 1.58^{\circ} \mathrm{vs} 3.87 \pm\right.$ $\left.1.59^{\circ}, p>0.05\right)$, Y-axis $\left(6.95 \pm 2.79^{\circ}\right.$ vs $\left.7.10 \pm 3.10^{\circ}, p>0.05\right)$ and Z-axis $\left(7.75 \pm 2.85^{\circ}\right.$ vs $\left.8.12 \pm 2.87^{\circ}, p>0.05\right)($ Fig. $8 \mathrm{C})$. 


\section{Discussion}

A mass of studies focusing on single-plane fluoroscopy systems have examined the joint motion [21, 22]. Banks et al. [23] and Acker et al. [21] reported the accuracy of single-plane fluoroscopy system in measuring the movement of joint replacement prosthesis. The error of measurement based on the single-plane study in other planes perpendicular to this plane could be up to 0.65 to $4 \mathrm{~mm}$, but the error of rotational measurement was small. However, the accuracy of singleplane 3D-to-2D registration technique was verified by RSA. Our study aimed to investigate the motion characteristics of hindfoot joints in the stance phase more comprehensively based on the above mentioned 5 events in stage $\triangle A A F D$.

The results of our study showed that, among the 4 tarsals in the hindfoot, the talus had the largest rotation deviation, but its value was only $0.87 \pm 0.32^{\circ}$, while the maximum rotation deviation in the subtalar joint was $-1.8 \pm 2.33^{\circ}$. Therefore, the measurement of rotation in our study was very accurate, and the rotation deviation did not exceed the deviation results of the uniplanar X-ray measurement technique reported in the relevant literature [15, 21, 22].

Our findings revealed that, in the early-stance phase (HS to FF), the navicular and calcaneus relative to the talus was more dorsiflexed, externally-rotated and everted in the flatfoot than in the normal foot. It was mainly due to the fact that at the early stage of stance phase, the calcaneus was the first to touch on the ground, and the lateral arch was lower than the medial arch, the lateral arch landed first, resulting in the calcaneus to be valgus relative to the talus. With the continued weight-bearing, the talus shifted medially due to stress, so the calcaneus was also relatively externally rotated. Due to the laxity of the medial structures in AAFD patients (mainly the laxity of the spring and deltoid ligaments), excessive plantarflexion and adduction occurred in the talus. With the advancement of gait to the midstance phase, the heel began to flatten and the foot tended to bear an increasingly higher weight. For the flatfoot, as the load increased significantly, the arch continued to collapse, causing the talus continued to move medially, and the scaphoid and calcaneus relative to the talus dorsiflexion and external rotation, resulting in the flatfoot navicular to have greater dorsiflexion and valgus external rotation than the normal navicular. Nevertheless, due to the small rotation amplitude of the calcaneus itself, no significant difference was observed in the rotation of normal calcaneus of the flatfoot during this period. After the mid-stance phase, the foot would begin to enter the late-stance phase (off-ground stage). For the normal foot, owing to the normal function of the posterior tibial tendon and its normal function for the navicular, the degree of internal rotation and inversion of the normal navicular was greater than that of the flatfoot. Similarly, owing to the linkage effect, the degree of internal rotation and inversion of the calcaneus was also greater than that of the flatfoot; on the contrary, due to the insufficient medial support of flatfoot, the degree of plantar flexion of the calcaneus and navicular was greater than that of the normal foot in the off-ground process. However, we found no significant difference in the movement of flatfoot and normal calcaneocuboid joints throughout the stance phase, which also confirms that the instability of the hindfoot of stage II flatfoot is mainly attributed to the subtalar and talonavicular joints, while the lesion has not yet involved the lateral calcaneocuboid joint. By aiming at stage II flatfeet and normal feet as the study subjects and the stance phase of gait as the main process, our study confirmed that there was hyperactivity in the subtalar joint and talonavicular joint of stage II flatfeet compared with normal feet in the earlyand mid-stance phase, and the motion of subtalar joint and talonavicular joint in flatfeet showed a state of decompensation in the late-stance phase. There was no significant difference in stage II flatfoot and normal calcaneocuboid joint motion throughout the phase. This is consistent with the conclusions regarding the subtalar and talonavicular joint instability derived from quasi-static studies of stage II flatfoot [16].

This study is subject to certain limitations. Firstly, stage II AAFD was not further subdivided into phase lla but generally classified as one category for analysis. Secondly, the experimental sample size was relatively small, which might bias the real results.

\section{Conclusions}


During the early- and mid-stance phase, excessive motion was observed in the subtalar and talonavicular joints in stage $\triangle A A F D$. During the late-stance phase, the motion of subtalar and talonavicular joints appeared to be in the decompensated state. During the whole stance phase, the motion of calcaneocuboid joint showed no significant difference between normal foot and stage $\triangle$ AAFD.

\section{Abbreviations}

AAFD: adult acquired flatfoot deformity; TNJ: talo-navicular joint; STJ: subtalar joint; CCJ: calcaneo-cuboid joint; HS: heel-strike; FF: foot-flat; MS: midstance; HO: heel-off; TO: toe-off; IRB: Institutional Review Board; RSA: radiographic stereophotogrammetry analysis; ROM: range of motion

\section{Declarations}

\section{Funding}

This study was supported by the National Natural Science Foundation of China $(81902303,82102632,82160412)$, Guangdong Basic and Applied Basic Research Foundation (2020A151501048), Medical Research Fund by Guangdong Provincial Health Commission (B2019085), Guangxi Natural Science Foundation (2020GXNSFBA297089), Shenzhen Science and Technology Project (JCYJ20190806164216661, RCBS20200714114856299), Liuzhou Science and Technology Project (2021CBB0106), and Clinical Research Project of Shenzhen Second People's Hospital (20203357028).

\section{Authors' contributions}

Conceptualization: ZD, JX ; methodology: ZD, JX; data acquisition: JX ; data elaboration: SC; data analysis: YL, FC; writing-original draft preparation, ZD, ZC; writing-review and editing: YL; funding acquisition: ZD, JX. All authors have read and agreed to the published version of the manuscript.

\section{Availability of data and materials}

Please contact author for data requests

\section{Ethics approval and consent to participate}

The in-vivo dataset utilized in the present study is part of a study approved by the ethical committee of the Fourth Affiliated Hospital of Guangxi Medical University, Liuzhou Workers' Hospital, Liuzhou, Guangxi, China with an approval number of LW2021011.The authors certify that the institution approved the investigation protocol and that all investigations were conducted in conformity with ethical standard of research.

\section{Consent for publication}

Signed Informed consent for participation in this study and to publish related anonymized information was obtained by all enrolled subjects.

\section{Competing interests}

The authors declare that they have no competing interests.

\section{References}


1. Flores DV, Mejía Gómez C, Fernández Hernando M, Davis MA, Pathria MN. Adult Acquired Flatfoot Deformity: Anatomy, Biomechanics, Staging, and Imaging Findings. Radiographics. 2019;39(5):1437-

1460. https://doi.org/10.1148/rg.2019190046.

2. Raduan FC, Coetzee JC, Den Hartog BD, Seybold JD, Cammack PM, Stone RM, et al. A New Approach for Stage 2 Adult Acquired Flatfoot Deformity. Foot Ankle Orthop.

2022;7(1):2473011421S00406. https://doi.org/10.1177/2473011421S00406.

3. Arain A, Harrington MC, Rosenbaum AJ. Adult Acquired Flatfoot. In: StatPearls. Treasure Island (FL): StatPearls Publishing; 2021.

4. Sammarco VJ. The talonavicular and calcaneocuboid joints: anatomy, biomechanics, and clinical management of the transverse tarsal joint. Foot Ankle Clin. 2004;9(1):127-145. https://doi.org/10.1016/S1083-7515(03)00152-9.

5. Demetracopoulos CA, Nair P, Malzberg A, Deland JT. Outcomes of a Stepcut Lengthening Calcaneal Osteotomy for Adult-Acquired Flatfoot Deformity. Foot Ankle Int. 2015;36(7):749-

755. https://doi.org/10.1177/1071100715574933.

6. Johnson KA, Strom DE. Tibialis posterior tendon dysfunction. Clin Orthop Relat Res. 1989;(239):196-206.

7. Flores DV, Mejía Gómez C, Fernández Hernando M, Davis MA, Pathria MN. Adult Acquired Flatfoot Deformity: Anatomy, Biomechanics, Staging, and Imaging Findings. Radiographics. 2019;39(5):1437-

1460. https://doi.org/10.1148/rg.2019190046.

8. Mann RA. Adult acquired flatfoot deformity. Treatment of dysfunction of the posterior tibial tendon. J Bone Joint Surg Am. 1997;79(9):1434.

9. Simonsen $\mathrm{OH}$, Revald P, Kjaer IL, Christensen M, Mølgaard C, Lass P. Tibialis posterior tendon dysfunction. An often neglected cause of painful adult ffflatfoot. Ugeskr Laeger. 2006;168(39):3314-3316.

10. Cifuentes-De la Portilla C, Larrainzar-Garijo R, Bayod J. Analysis of biomechanical stresses caused by hindfoot joint arthrodesis in the treatment of adult acquired flatfoot deformity: A finite element study. Foot Ankle Surg. 2020;26(4):412-420. https://doi.org/10.1016/j.fas.2019.05.010.

11. Bluman EM, Title Cl, Myerson MS. Posterior tibial tendon rupture: a refined classification system. Foot Ankle Clin. 2007;12(2):233-49. https://doi.org/10.1016/j.fcl.2007.03.003.

12. Alvarez RG, Marini A, Schmitt C, Saltzman CL. Stage I and II posterior tibial tendon dysfunction treated by a structured nonoperative management protocol: an orthosis and exercise program. Foot Ankle Int. 2006;27(1):28. https://doi.org/10.1177/107110070602700102.

13. Wang C, Wang H, Cao S, Wang S, Ma X, Wang X, et al. Pathological kinematic patterns of the tarsal complex in stage II adult-acquired flatfoot deformity. J Orthop Res. 2019;37(2):477-482. https://doi.org/10.1002/jor.23821.

14. Zhang $Y$, Xu J, Wang X, Huang J, Zhang C, Chen L, et al. An in vivo study of hindfoot 3D kinetics in stage II posterior tibial tendon dysfunction (PTTD) flatfoot based on weight-bearing CT scan. Bone Joint Res. 2013;2(12):25563. https://doi.org/ 10.1302/2046-3758.212.2000220.

15. Mok KM, Fong DT, Krosshaug T, Hung AS, Yung PS, Chan KM. An ankle joint model-based image-matching motion analysis technique. Gait Posture. 2011;34(1):71-75. https://doi.org/10.1016/j.gaitpost.2011.03.014.

16. Xu J, Zhang Y, Muhammad H, Wang X, Huang J, Zhang C, et al. In vivo three-dimensional analysis of hindfoot kinematics in stage II PTTD flatfoot. J Orthop Sci. 2015;20(3):488-497. https://doi.org/10.1007/s00776-015-06984.

17. Shultz R, Kedgley AE, Jenkyn TR. Quantifying skin motion artifact error of the hindfoot and forefoot marker clusters with the optical tracking of a multi-segment foot model using single-plane fluoroscopy. Gait Posture. 2011;34(1):44-48. https://doi.org/10.1016/j.gaitpost.2011.03.008.

Page $10 / 12$ 
18. Aronson AS, Hoist L, Selvik G. An instrument for insertion of radiopaque bone markers. Radiology. 1974;113(3):733734. https://doi.org/10.1148/113.3.733.

19. Kidder SM, Abuzzahab FS Jr, Harris GF, Johnson JE. A system for the analysis of foot and ankle kinematics during gait. IEEE Trans Rehabil Eng. 1996;4(1):25-32. https://doi.org/10.1109/86.486054.

20. Cross JA, McHenry BD, Molthen R, Exten E, Schmidt TG, Harris GF. Biplane fluoroscopy for hindfoot motion analysis during gait: A model-based evaluation. Med Eng Phys. 2017;43:118-

123. https://doi.org/10.1016/j.medengphy.2017.02.009.

21. Acker S, Li R, Murray H, John PS, Banks S, Mu S, et al. Accuracy of single-plane fluoroscopy in determining relative position and orientation of total knee replacement components. J Biomech. 2011;44(4):784787. https://doi.org/10.1016/j.jbiomech.2010.10.033.

22. Scarvell JM, Pickering MR, Smith PN. New registration algorithm for determining 3D knee kinematics using CT and single-plane fluoroscopy with improved out-of-plane translation accuracy. J Orthop Res. 2010;28(3):334340. https://doi.org/10.1002/jor.21003.

23. Banks SA, Hodge WA. Accurate measurement of three-dimensional knee replacement kinematics using single-plane fluoroscopy. IEEE Trans Biomed Eng. 1996;43(6):638-649. https://doi.org/10.1109/10.495283.

\section{Figures}

\section{Figure 1}

CT image of the ankle joint in coronal (A), sagittal (B) and transverse (C) views. (D) Setting of talus coordinate axis.

\section{Figure 2}

(A) X-ray later imaging of the ankle joint from plantar flexion to dorsiflexion of the specimen with tantalum beads implanted. (B) Matching of tantalum beads by software

\section{Figure 3}

Macro view and X-ray of Stage II AAFD. (A, D) Forefoot abduction deformity. (B, E) Medial arch collapse. (C, F) Hindfoot valgus. 


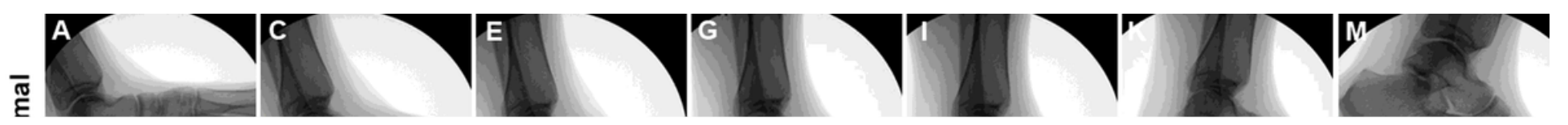

\section{Figure 4}

Seven key gait postures in the normal foot and stage II AAFD. (A, B) Test heel ready to stand and contralateral heel off ground. (C, D) Test heel ready to touch ground. (E, F) Test foot in mid-stance and contralateral foot toe off ground. (G,

H) Test foot in mid-stance and contralateral foot in swing phase. $(\mathrm{I}, \mathrm{J})$ Test foot ready to heel off ground. $(\mathrm{K}, \mathrm{L})$ Test foot heel off ground. $(M, N)$ Test foot toe off ground.

\section{Figure 5}

3D-to-2D matching of subtalar joint (A-S), talonavicular joint (B-T) and calcaneocuboid joint (C-U) in the 7 step postures.

\section{Figure 6}

Rotation trend of subtalar joint, talonavicular joint, and calcaneocuboid joint of all normal foot and flatfoot volunteers from the first step to the seventh step around $X-, Y$ - and Z-axes.

\section{Figure 7}

Average trend of rotation of subtalar joint, talonavicular joint, and calcaneocuboid joint of all normal foot and flatfoot volunteers from the first step to the seventh step around X-, Y- and Z-axes.

\section{Figure 8}

ROM changes of ankle joints of normal foot and stage II AAFD (motiondata represents motion data; motionaxis represents motion axis; motion31, motion53 and motion75 represent the first step to the third step, the third step to the fifth step, and the fifth step to the seventh step respectively). (A) Subtalar joint. (B) Talonavicular joint. (C) Calcaneocuboid joint. 